\title{
Ontogeny of adrenal-like glucocorticoid synthesis pathway and of 20a-hydroxysteroid dehydrogenase in the mouse lung
}

Eric Boucher ${ }^{1,3}$, Pierre R Provost ${ }^{1,2,3}$ and Yves Tremblay ${ }^{1,2,3^{*}}$

\begin{abstract}
Background: Glucocorticoids exert recognized positive effects on lung development. The genes involved in the classical pathway of glucocorticoid synthesis normally occurring in adrenals were found to be expressed on gestation day (GD) 15.5 in the developing mouse lung. Recently, expression of two of these genes was also detected on GD 17.5 suggesting a more complex temporal regulation than previously expected. Here, we deepen the knowledge on expression of "adrenal" glucocorticoid synthesis genes in the mouse lung during the perinatal period and we also study expression of the gene encoding for the steroid inactivating enzyme 20a-hydroxysteroid dehydrogenase (20a-HSD).

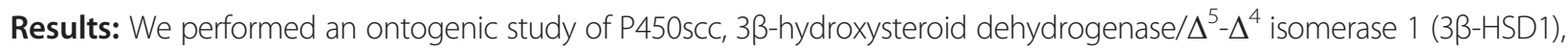
21-hydroxylase, $11 \beta$-hydroxylase, $11 \beta$-HSD1, and 11ß-HSD2 expression up to post natal day (PN) 15. The substrate (progesterone) and the product (deoxycorticosterone) of 21-hydroxylase are substrates of 20a-HSD, thus 20a-HSD (Akr1 18) gene expression was investigated. In lung samples collected between GD 15.5 and PN 15, 11ß-hydroxylase was only detected on GD 15.5. In contrast, all the other tested genes were expressed throughout the analyzed period with different temporal expression patterns. P450scc, 21-hydroxylase, 20a-HSD and 11ß-HSD2 mRNA levels increased after birth with different patterns including an increase from PN 3 with a possible sex difference for 21-hydroxylase mRNA. Also, the 21-hydroxylase protein was observed by Western blot in perinatal lungs with higher levels after birth.

Conclusion: Progesterone is present at high levels during gestation and the product of 21-hydroxylase, deoxycorticosterone, can bind the glucocorticoid receptor with an affinity close to that of corticosterone. Detection of 21-hydroxylase at the protein level during antenatal lung development is the first evidence that the adrenal-like glucocorticoid synthesis pathway detected during lung development has the machinery to produce glucocorticoids in the fetal lung. Glucocorticoids from lung 21-hydroxylase appear to modulate lung ontogenesis through paracrine/ intracrine actions.
\end{abstract}

Keywords: 21-hydroxylase, $11 \beta$-hydroxylase, Corticosterone, Development, Fetal, Glucocorticoid, Progesterone, Steroidogenesis, Mineralocorticoid, $11 \beta-H S D$

\footnotetext{
* Correspondence: yves.tremblay@crchul.ulaval.ca

'Reproduction, mother and youth health, Centre de recherche du CHU de

Québec, Québec, QC, Canada

2Department of Obstetrics/Gynecology \& Reproduction, Faculty of Medicine,

Université Laval, Québec, QC, Canada

Full list of author information is available at the end of the article
} 


\section{Background}

Glucocorticoids (GCs) play an essential role in fetal lung development $[1,2]$. They exert various effects including thinning of alveolar septa, increase in the number of type I pneumonocytes, decrease in pneumonocyte cell division, and stimulation of secretion of fibroblast paracrine factors that play a role in type II pneumonocyte maturation [3]. Glucocorticoid receptor-deficient mice were reported to die within a few hours after birth because of respiratory failure [4], showing the importance of GCs in the lung development process. The requirement for GCs in normal lung development was also demonstrated with a CRH knockout (KO) mouse model. $\mathrm{CRH} \mathrm{KO}$ homozygous fetuses from CRH KO homozygous mothers were delivered normally at term, but died on the first day of life with an overall failure in lung development, except when GCs were administered to pregnant dams $[2,5]$. The overall failure of lung development was characterized by hypercellularity of the mesenchymal compartment and decreased expression of mRNAs associated with mature lung epithelial cells such as those of surfactant protein (SP)-A, SP-B and CCP10.

The endogenous GCs accessible to the developing lung originate from two sources. They can be provided by adrenals through the classical pathway of GC synthesis from cholesterol, or by the lung where cortisone or 11dehydrocorticosterone (11-DHC, rodent) can be reactivated to cortisol or corticosterone, respectively. In the rodent adrenals, cytochrome P450 side-chain cleavage (P450scc), 3 $\beta$ hydroxysteroid dehydrogenase $/ \Delta^{5}-\Delta^{4}$ isomerase (3 $\beta$-HSD), 21-hydroxylase, and 11 -hydroxylase are involved in GC synthesis (Figure 1). All these enzymes play a similar role in the adrenals of the human and many other non-rodent mammals, except that cytochrome P450c17 converts pregnenolone and progesterone into $17 \mathrm{OH}$-pregnenolone and $17 \mathrm{OH}$-progesterone, respectively. This leads to the production of the active GC cortisol instead of corticosterone. In peripheral tissues including the lung, GC synthesis was considered for many years to be limited to cortisol (human) and corticosterone (rodents) reactivation by $11 \beta$-hydroxysteroid dehydrogenase type 1 (11 $\beta$-HSD1) [6] following their prior inactivation by $11 \beta$-HSD2. This perception is changing since genes normally involved in the classical adrenal pathway of GC synthesis were found to be expressed in some peripheral sites such as thymus, skin, and brain [7]. We are among the pioneers that have described expression of the adrenal genes outside adrenals [8].

In 2005, we reported that the four genes encoding for the enzymes catalyzing corticosterone synthesis from cholesterol and StAR were expressed in the fetal lung on gestation day (GD) 15.5 in the Balb/c mouse [8]. StAR is essential to this synthesis pathway since it plays a role in the intramitochondrial movement of cholesterol [9]. In fetal lungs studied up to GD 18.5, 11 $\beta$-hydroxylase mRNA was found only on GD 15.5, which led to the initial conclusion that the adrenal pathway of GC synthesis should be expressed only on GD 15.5 in the developing lung. Further studies showed that $3 \beta-$ HSD1 and 21 hydroxylase were still expressed on GD17.5 [10,11]. This

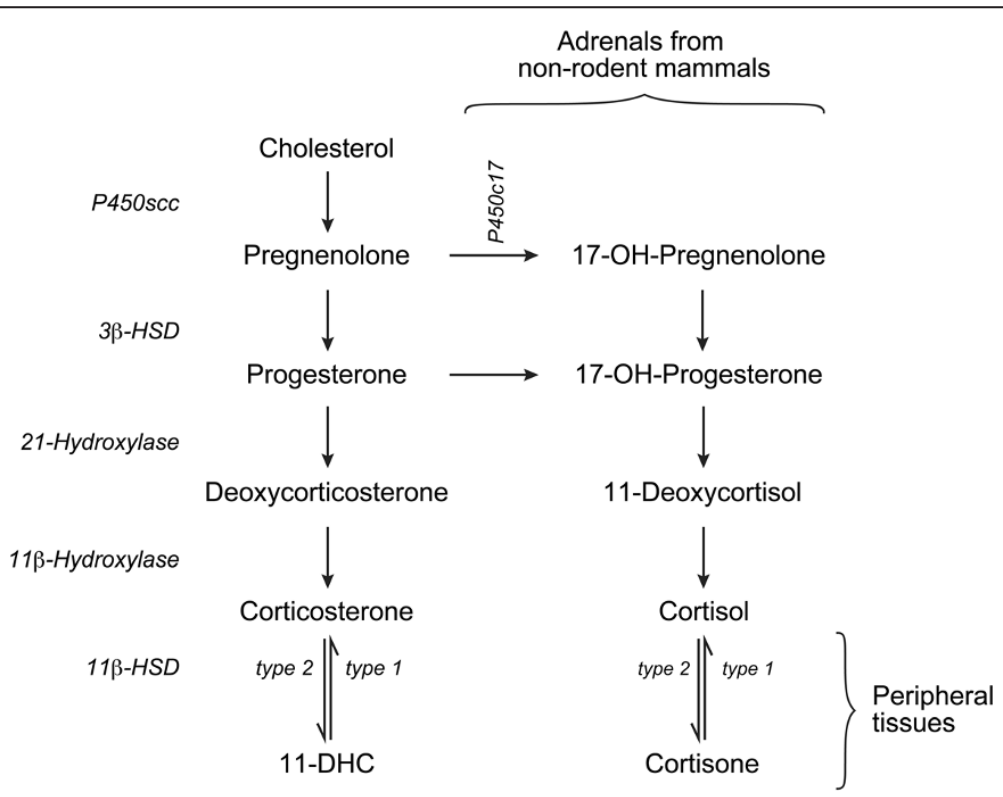

Figure 1 Glucocorticoid synthesis pathway in rodent and non-rodent mammals. Corticosterone (rodent) and cortisol (non-rodent mammals) are the most potent circulating GCs. Their production from cholesterol in adrenals correspond to the classical pathway of GC synthesis. There is no P450c17 enzyme in the rodent adrenal. Cell-specific 11ß-HSD-catalyzed reactions occur in peripheral tissues. During the last decade, expression of some or all the enzymes catalyzing $\mathrm{GC}$ production from cholesterol has been observed in some non-adrenal tissues including the developing lung. 
is important because the product of 21-hydroxylase, deoxycorticosterone (DOC), is known to bind the glucocorticoid receptor [12-15] with an $\mathrm{IC}_{50}$ value of $70 \mathrm{nM}$ compared to $60 \mathrm{nM}$ for corticosterone [15]. Therefore, the impact of 21-hydroxylase on lung development may be exerted during a longer period, but the exact developmental time remains to be characterized.

The aim of the present study was to deepen the knowledge on expression of "adrenal" glucocorticoid synthesis genes in the mouse lung during the perinatal period and to study expression of the $20 \alpha-\mathrm{HSD}$ gene encoding for a steroid inactivating enzyme active on c21 steroids. An ontogenic study of P450scc, 3 $\beta$-HSD1, 21-hydroxylase, and $11 \beta$-hydroxylase expression in the mouse developing lung was performed up to post-natal day (PN) 15. Genes encoding for $11 \beta$-HSD1 and 11 $\beta$-HSD2 were included for comparison. In addition, the expression of $A k r 1 c 18$ gene, encoding for $20 \alpha-\mathrm{HSD}$, was included because $20 \alpha-$ HSD is active on the substrate (progesterone) and on the product (DOC) of 21-hydroxylase. This gene has never been studied in the lung. Because a sex difference in the timing of expression of the adrenal-like pathway of GC synthesis was proposed on GD 15.5 in the fetal lung [8], both sexes were studied separately. Finally, an ontogenic study of levels of 21-hydroxylase protein is also included.

\section{Results}

Expression of genes of the "adrenal" pathway of GC synthesis in the antenatal lung after GD 15.5 and in the post-natal developing lung

The temporal and sexual expression profiles of P450scc, $3 \beta$-HSD1, 21-hydroxylase, and 11 $\beta$-hydroxylase genes were determined using cDNA prepared from pooled male and female lung tissues (one pool/sex/litter) from GD 15.5 to PN 15. The $11 \beta$-hydroxylase transcript was detected at significant levels on GD 15.5, but not between GD 16.5 and PN 15 inclusively (data not shown). These data are in agreement with previously published data obtained between GD 15.5 and $18.5[8,10]$, and on GD 17.5 [10]. Conversely, the P450scc, 3 $\beta$-HSD1 and 21-hydroxylase genes were expressed after GD 15.5 at least up to PN 15 in the alveolar stage (Figure 2). In fact, mRNAs were detected for these three genes in all analyzed samples, exhibiting specific temporal expression patterns. A two-way ANOVA showed that P450scc mRNA levels varied significantly according to developmental age, but not sex (Table 1). In fact, a significant 18-fold increase was observed from GD 15.5 to GD 19.5, followed by a significant 2.3-fold increase between PN 0 and PN 3, and a marked significant 28-fold decrease from PN 7 to PN 15 (Figure 2A-B). Expression of $3 \beta-\mathrm{HSD} 1$ did not show significant temporal or sexual regulation, although a slight significant trend for decreased expression was observed over developmental time (Figure 2C-D and Table 1). A statistical analysis showed a significant influence of age but not of sex or sex"age on 21-hydroxylase expression (Table 1). Hence, 21-hydroxylase expression was stable from GD 15.5 to PN 3, presented a 4.3-fold increase between PN 3 and PN 7, and remained stable until PN 15 (Figure 2E-F). Inter-litter variability was somewhat higher on PN 7 and PN 15 for 21-hydroxylase, which might explain why no statistically significant sex difference was found despite the fact that all the 6 litters of this period showed higher expression levels for females compared to males (Figure 2E).

\section{Sexual and temporal regulation of 20a-HSD expression in the antenatal and post-natal developing lungs}

Progesterone and DOC inactivation can be achieved by $20 \alpha$-HSD activity, which was observed in cytosolic fractions of adult mouse lungs [16] and in adult human lung slices [17]. However, an ontogenic study of $20 \alpha-H S D$ expression has never been reported in the developing lung. To perform this study, 20 $\alpha$-HSD mRNA levels were measured in mouse developing lung samples collected at various developmental times. Expression of 20 $\alpha-\mathrm{HSD}$ was observed in all samples analyzed from GD 15.5 to PN 15 (Figure 3). A statistically significant variation over developmental time was observed (Table 1) including a marked post-natal increase until PN 3 for both sexes. While no significant sex difference was detected by twoway ANOVA, a male-specific decrease of 19-fold before birth was observed (Figure 3). Expression levels of $20 \alpha-$ HSD were higher than those of 21-hydroxylase during near all the developmental period studied, with a difference of 5.4-fold in favor of $20 \alpha-$ HSD on PN 3.

\section{$11 \beta-H S D 1$ and $11 \beta-H S D 2$ expression profiles from GD 19.5 to PN 15}

A qPCR study of $11 \beta$-HSD1 and $11 \beta-H S D 2$ expression was reported in the fetal lung between GD 15.5 and 18.5 [8]. Here, the study covers the GD 19.5-PN 15 period. Only little changes were measured over developmental time for $11 \beta$-HSD1. In contrast, the $11 \beta-H S D 2$ mRNA levels presented a marked statistically significant increase after birth (Figure 4 and Table 1).

\section{1-Hydroxylase protein during lung development}

The levels of the 21-hydroxylase protein were analyzed by Western blotting of whole lung protein samples and of microsomal fractions. Our data show that not only the 21-hydroxylase mRNA but also the 21-hydroxylase protein are present in the perinatal lung (Figure 5 and data not shown). Specific signals were higher in lung samples collected after birth compared to those obtained during gestation (Figure 5). Because 21-hydroxylase is a microsomal protein, microsome preparations were also 


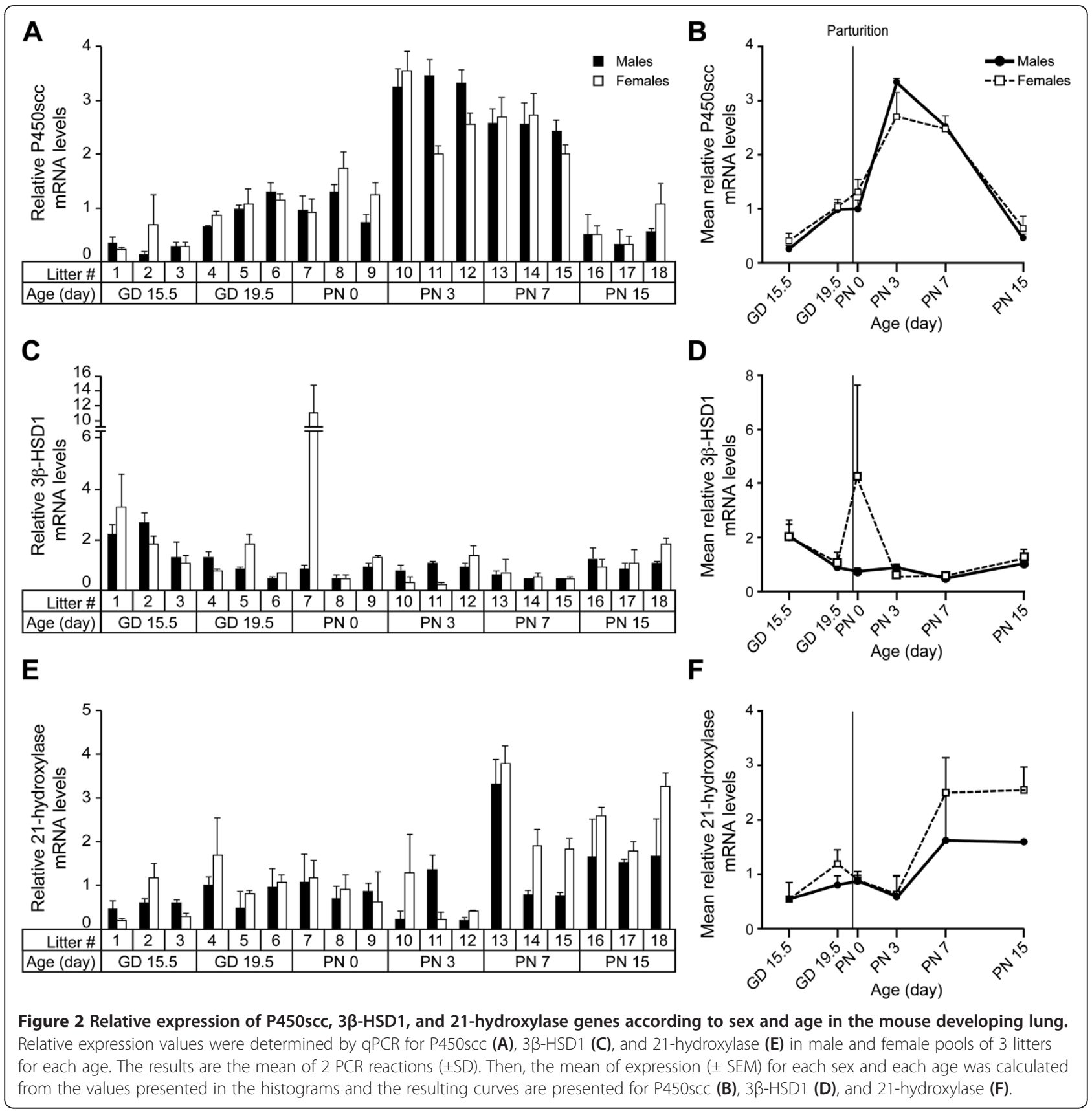

studied. The upper unspecific signal observed with total protein extracts (Figure 5A) was undetected or close to the background with microsomal fractions (Figure 5B). The most intense signals were observed with samples from PN 7 and PN 16. This increase in 21-hydroxylase protein levels correlates with the increase in mRNA levels described above (Figure 2E-F). Intermediate protein levels were observed in samples from PN 3 (one individual) and PN 2 (pool from one litter). This can be explained by slight variations in mRNA levels from individual to individual or from litter to litter, as those observed in Figure 2E. No sex difference was observed at the specific developmental times tested, except on PN 15 , when a slight difference in favor of females was observed (data not shown).

\section{Discussion}

This is the first ontogenic study performed in the developing lung up to PN 15 studying expression of the four genes normally involved in the adrenal pathway of glucocorticoid synthesis from cholesterol. 11 $\beta$-hydroxylase was previously studied in the developing lung after GD 15.5 (from GD 15.5 to GD 18.5 [8] and on GD 17.5 [10]) and no detectable levels of $11 \beta$-hydroxylase mRNA were found 
Table 1 Two-way analysis of variance (ANOVA) of expression of murine genes involved in C-21 steroid metabolism in the developing lung

\begin{tabular}{lccc}
\hline Gene & \multicolumn{3}{c}{ P values } \\
\cline { 2 - 4 } & Age Sex & Age & Sex \\
\hline P450scc & 0.6606 & $<0.0001$ & 0.3264 \\
3ß-HSD1 & 0.1387 & 0.0630 & 0.6889 \\
21-hydroxylase & 0.7968 & 0.0029 & 0.2728 \\
20a-HSD & 0.3141 & 0.0003 & 0.4667 \\
$11 \beta-H S D 1$ & 0.3073 & 0.0104 & 0.8879 \\
$11 \beta-H S D 2$ & 0.9989 & $<0.0001$ & 0.9233 \\
\hline
\end{tabular}

after GD 15.5. Here, studying the developing lung at several time points from GD 15.5 to PN 15, we conclude that 11ß-hydroxylase mRNA can be found only on GD 15.5 in the developing lung. In contrast, P450scc, 3 $\beta$-HSD1 and 21-hydroxylase mRNAs were found in all the analyzed samples from GD 15.5 to PN 15. Moreover, the 21-hydroxylase protein was observed in all the analyzed samples from GD 15.5 to PN 16. This is important because the substrate of this enzyme, progesterone, is present during gestation while the product of this enzyme, DOC, has the ability to bind the glucocorticoid receptor [12-15] with an $\mathrm{IC}_{50}$ value of $70 \mathrm{nM}$ compared to $60 \mathrm{nM}$ for corticosterone [15]. Therefore, the developing lung possesses the machinery to produce active glucocorticoids, at least during gestation, using circulating progesterone as a substrate.

A transient sex difference in $20 \alpha$-HSD mRNA levels was observed on GD 19.5 in the developing lung, when the female values were 19-fold higher than the male values (Figure 3). A sex difference in $20 \alpha-H S D$ expression was also reported in the mouse adrenal [18]. In that tissue, 20 $\alpha$-HSD expression was restricted to the transient X-zone located between the cortex and the medulla.
The presence of the $20 \alpha-H S D$ protein in adrenals was shown to correlate with the presence of the X-zone. On PN 10, no sex difference was observed in the lung in our experiments, whereas a sex difference was found in the adrenal where both $20 \alpha$-HSD and the X-zone were absent specifically in the male tissue. Therefore, no relationship between the sex differences observed in the developing lung and in adrenals can be established. Sex differences in 20 $\alpha$-HSD mRNA levels with higher levels for females were also observed in the skin, liver, and kidney obtained from adult mice [19]. It was suggested that $20 \alpha$-HSD may play a role in reducing intracellular levels of progesterone originating from the circulation [19]. In the lung, except on GD 19.5, no significant sex difference was observed in $20 \alpha$-HSD mRNA levels, which is in line with the absence of sex difference in perinatal progesterone levels in rodents [20]. However, progesterone levels are decreasing in late gestation to reach very low levels after birth, which is not the case for $20 \alpha-H S D$ expression.

The expression of $20 \alpha-\mathrm{HSD}$ in the developing lung is compatible with a function of this enzyme in modulation of progesterone receptor occupancy, but our data also suggest that another function should exist in the lung. Indeed, we observed a marked increase in 20 $\alpha$-HSD expression after birth in both sexes. Interestingly, this increase just preceded the increase in 21-hydroxylase expression. Therefore, we propose that $20 \alpha$-HSD could play a role related to the glucocorticoid synthesis pathway. This enzyme can inactivate both the substrate (progesterone) and the product (DOC) of the 21-hydroxylase [18]. Thus, the lung $20 \alpha-H S D$ activity should influence glucocorticoid receptor occupancy.

The coexistence of GC synthesizing and inactivating activities in the developing lung strongly suggests regionalization of GC action. Intracrine as well as paracrine GC

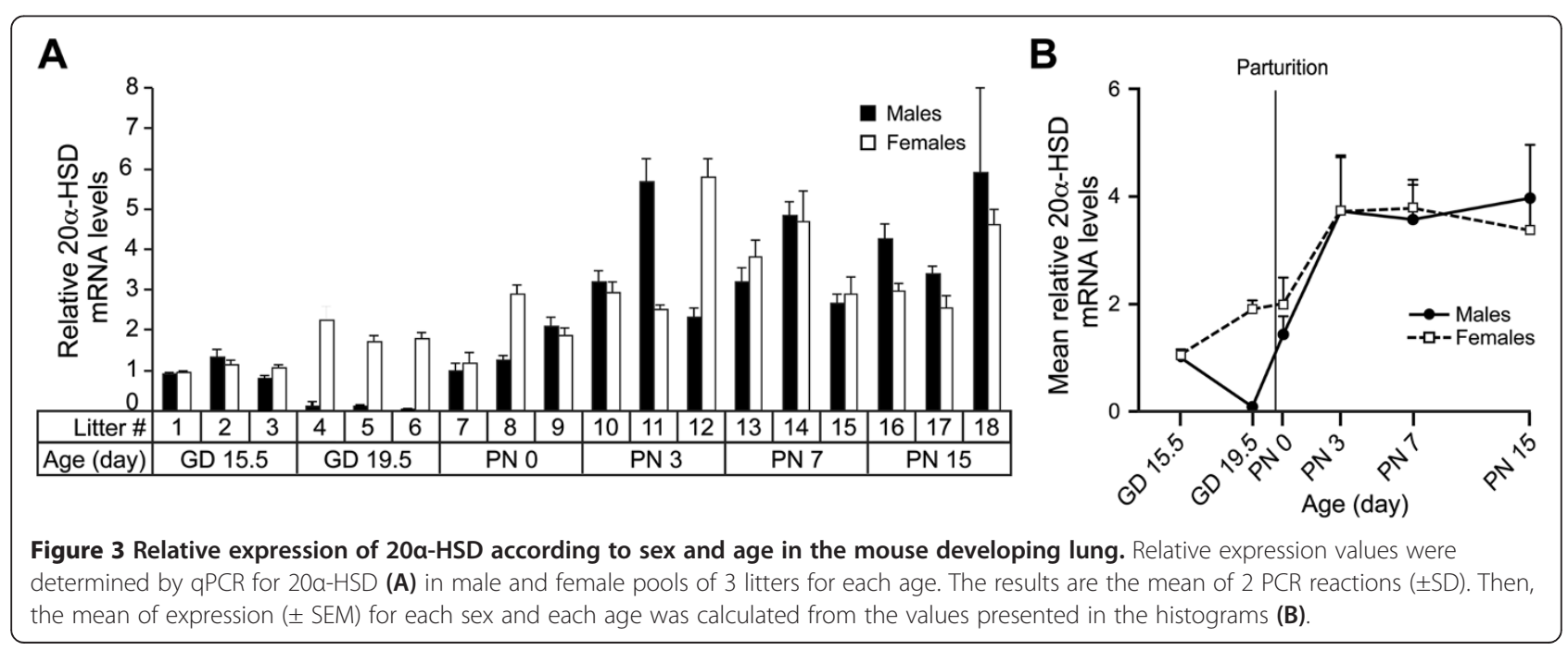




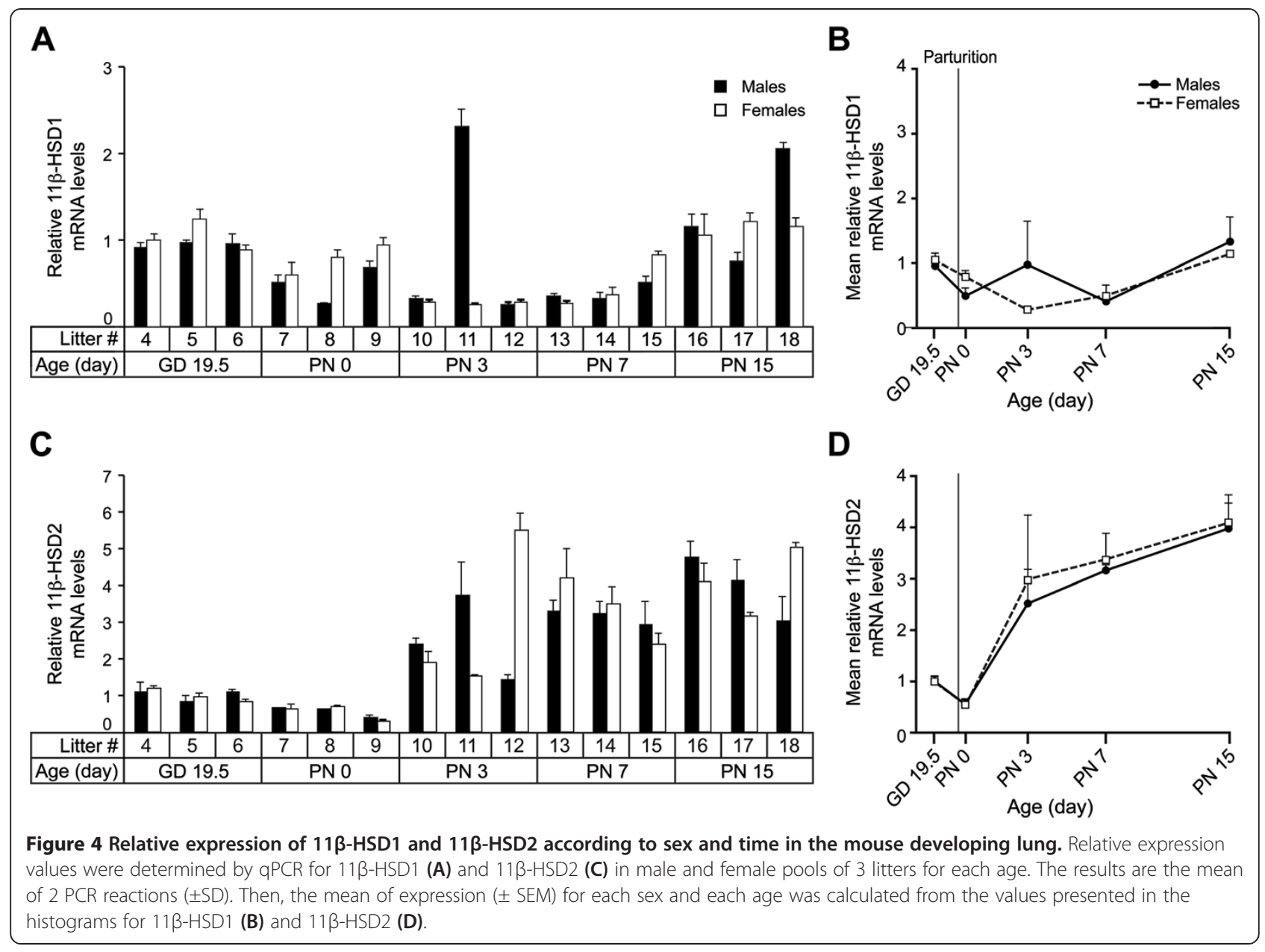

actions in the developing lung are compatible with our data. The concept of intracrine action was first demonstrated for dihydrotestosterone in the prostate [21,22]. It is defined as the action of newly-formed active steroids within the cells that synthesized them. As shown in Figure 6, the 21-hydroxylase activity changes the affinity of the substrate from progesterone receptor to glucocorticoid receptor, while the $20 \alpha-H S D$ activity controls the availability of active steroids (progesterone and DOC). Therefore, 20 $\alpha$ HSD may be involved in the fine tuning of both progesterone receptor occupancy, through its impact on progesterone levels, and glucocorticoid receptor occupancy, through the regulation of the levels of the substrate (progesterone) and product (DOC) of 21-hydroxylase.

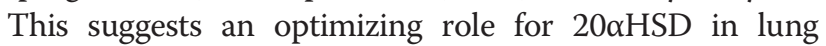
development.

$11 \beta-H S D 2$ is expressed in aldosterone-selective target cells and prevents illicit occupation of mineralocorticoid receptor (MR) by GCs [23,24]. A role for mineralocorticoids is proposed in lung development [25] where coexpression of $11 \beta-\mathrm{HSD} 2$ and MR genes were found $[26,27]$. MR is proposed to be involved in the control of reabsorption of pulmonary fluid by $\mathrm{ENaC}$, which is essential to the transition from uterine to aerial life at birth. However, $\mathrm{ENaC}$ is also modulated by glucocorticoids in the developing lung $[28,29]$. The increase in $11 \beta$-HSD2 mRNA observed in our experiment occurred after parturition and correlated well with the beginning of septation. Therefore, we propose that the process of septation may require a greater specificity of MR to mineralocorticoids.

\section{Conclusion}

Our data show that expression in the developing lung of most of the genes involved in the adrenal-like glucocorticoid synthesis pathway is maintained beyond GD 15.5. The gene expression results are compatible with corticosterone formation on GD 15.5, and DOC formation after GD 15.5, both steroids having the capability to bind the glucocorticoid receptor. The presence of the 21-hydroxylase protein showed that the fetal lung contains the machinery catalyzing DOC formation from progesterone, which is present in the fetal circulation. Co-expression of 21-hydroxylase and $20 \alpha-\mathrm{HSD}$ in the 


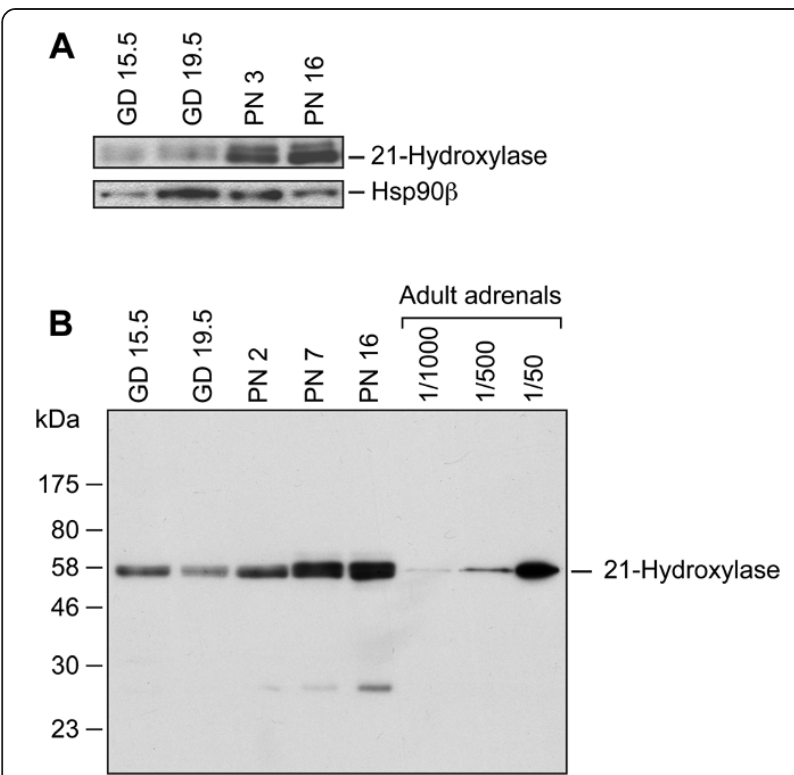

Figure 5 21-hydroxylase protein in the mouse developing lung. A Western blot analysis of the 21-hydroxylase protein is presented for whole lung protein extracts $(50 \mu \mathrm{g})$ (panel A) and microsomal fractions (50 $\mathrm{mg}$ of microsomal proteins) (panel B) for the indicated developmental times. For the study of total protein extracts, levels of Hsp90 $\beta$ are shown as a loading control. Total protein extracts were prepared with the lungs from one individual for each time point, whereas microsomal fractions were prepared using a pool of lungs from all the fetuses/neonates of one litter for each time point. Microsomes from adult adrenals were used as control. The proportion of adrenal microsomal proteins loaded on the gel compared to the amount loaded for the lungs is indicated $(1 / 1000=50 \mathrm{ng}$ microsomal proteins, $1 / 500=100 \mathrm{ng}$, and 1/50 $=1 \mu \mathrm{g}$ ). Each pannel corresponds to a different gel.

developing lung strongly suggests that this tissue does not act as a classical endocrine gland, but is rather a site of intracrine/paracrine actions.

\section{Methods}

\section{Animals and tissue preparation}

The protocol and procedures were approved by the animal care and use committee and the institutional review board of the Centre de Recherche du CHU de Québec (CPA-CRCHUQ; protocols no. 2005-156, 2008-071 and 2011-053). All animals were kept under a $12 \mathrm{~h}$ light/dark cycle and received water and feed ad libitum. Balb/c (Mus musculus) females at the estrus stage and males of the same strain were mated overnight $(16 \mathrm{~h})$. The day of copulatory plug was considered as GD 0.5 while the beginning of PN 0 corresponded to parturition. Pregnant females were kept into individual cages until sacrifice. All pregnant females were euthanized by $\mathrm{CO}_{2}$ inhalation. Pups were sacrificed either by decapitation following hypothermia-induced anesthesia (GD 15.5 to PN 5), or by intra-peritoneal injection of Euthanyl (PN 6 to PN 16; pentobarbital sodium, Bimeda-MTC, Cambridge, ON,

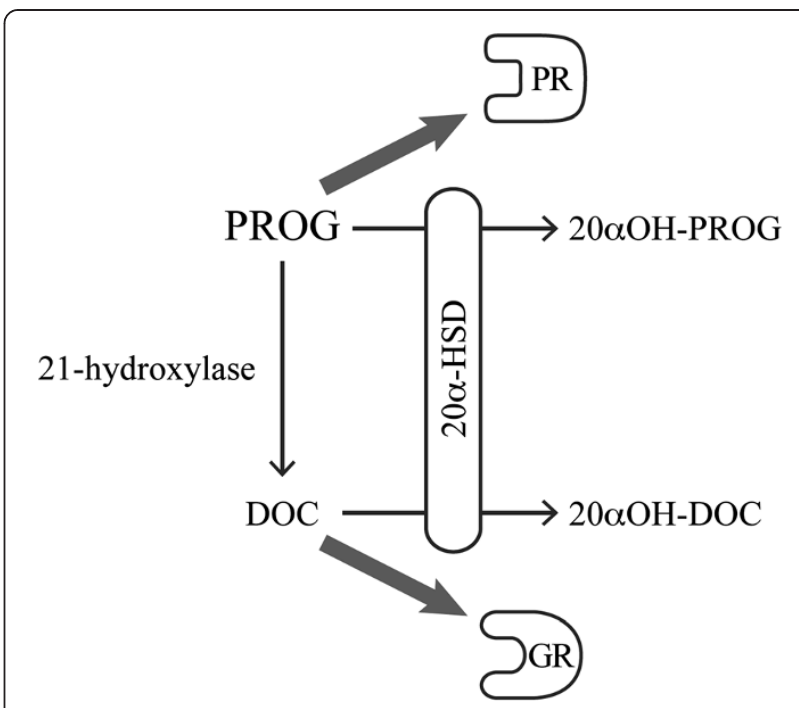

Figure 6 Effects of 21-hydroxylase and 20a-HSD on progesterone receptor and glucocorticoid receptor occupancy. PROG, progesterone; PR progesterone receptor; GR, glucocorticoid receptor.

Canada). Sex of fetuses/neonates was determined by gonadal morphology. Fetal and neonatal lungs were individually flash-frozen for use in $\mathrm{qPCR}$ and protein extraction. Adrenals from dams were also collected and flash-frozen.

\section{Real-time quantitative PCR of target and normalization genes}

For each litter, flash-frozen tissues were pooled according to sex. Total RNA was extracted using Tri-reagent (Molecular Research Center, Cincinnati, OH, USA) according to the protocol of the manufacturer. Each RNA sample was purified on a $\mathrm{CsCl}$ gradient [30], using a TLA 120.2 rotor in an Optima MAX centrifuge (Beckman, Mississauga, ON, Canada). An aliquot of $4 \mu \mathrm{g}$ of each total RNA sample was treated with DNase I $(0.25 \mathrm{U} / \mu \mathrm{g}$ of RNA), and then reversed transcribed using Superscript II (Life Technologies, Burlington, ON, Canada) and hexameric random primers (pd $[\mathrm{N}]_{6}$, Life Technologies) for $50 \mathrm{~min}$ at $42^{\circ} \mathrm{C}$ in a final volume of $20 \mu \mathrm{l}$ according to the protocol of the manufacturer. Reverse transcriptase was inactivated by heating at $70^{\circ} \mathrm{C}$ for $15 \mathrm{~min}$. The resulting cDNAs were diluted tenfold before qPCR analyses. The same cDNA preparations were used for all of the analyzed genes. The qPCR reactions were performed on a LightCycler instrument (Roche, Montreal, QC, Canada) using LightCycler-FastStart DNA Master SYBR Green I kits (Roche). After qPCR enzyme activation (10 $\mathrm{min}$, $95^{\circ} \mathrm{C}$ ), PCR cycles were performed as follows: $5 \mathrm{Sec}$ $95^{\circ} \mathrm{C}$ (denaturation); $5 \mathrm{sec}$ at the annealing temperature; $20 \mathrm{Sec} 72^{\circ} \mathrm{C}$ (elongation); $5 \mathrm{sec}$ at the temperature of fluorescence intensity reading. The specific primer sequences and qPCR conditions are presented in Table 2 
Table 2 Analyzed murine genes and their specific real-time QPCR conditions

\begin{tabular}{|c|c|c|c|c|c|}
\hline \multirow{2}{*}{$\begin{array}{l}\text { Mouse } \\
\text { genes }\end{array}$} & \multirow{2}{*}{$\begin{array}{c}\text { Accession } \\
\text { number (NCBI) }\end{array}$} & \multirow[t]{2}{*}{ Oligonucleotides (sense/antisense) } & \multirow{2}{*}{$\begin{array}{l}\text { Amplicon } \\
\text { length (bp) }\end{array}$} & \multicolumn{2}{|c|}{ QPCR conditions ${ }^{\mathrm{a}}$} \\
\hline & & & & Ann. $\mathrm{T}\left({ }^{\circ} \mathrm{C}\right)$ & Acq. $\mathrm{T}\left({ }^{\circ} \mathrm{C}\right)$ \\
\hline Cyp11a1 & NM_019779 & ATCCGGGCTTCTTTCCCAATC/GGATGGGGTTCTCAGGCATC & 249 & 64 & 86 \\
\hline$H s d 3 b 1$ & NM_008293 & TGCCAGGGCATCTCTGTTGTC/TCTGTTCCTCGTGGCCATTCA & 220 & 64 & 84 \\
\hline Cyp21a1 & NM_009995 & TCACGACTGTGTCCAGGACTTG/TTCGTCTTTGCCATCCCTTTG & 250 & 67 & 84 \\
\hline AkriC18 & NM_1340662.2 & GCACCATAGGCAACCAGAAC/TCTCATTCATTTCCCAGTGTCTC & 312 & 54 & 78 \\
\hline Cyp11b1 & NM_001033229 & CTGGGACAGTCCTCAATGTGA/ATCCGCACATCCTCTTTCTCTT & 244 & 62 & 87 \\
\hline Hsd11b1 & NM_008288 & GGCCAGCAAAGGGATTGGAAG/TाTCCCAGCCAAGGAGGAGA & 401 & 66 & 85 \\
\hline Hsd11b2 & NM_008289 & TGGCTGACGTGGGACTGTCT/TTGGAGCAGCCAGGCTTGATA & 277 & 63 & 87 \\
\hline Gapdh & NM_008084 & GTCGGTGTGAACGGATTTG/AAGATGGTGATGGGCTTCC & 215 & 61 & 84 \\
\hline Hmbs & NM_013551 & GGAATGCATGTATGCTGTGGG/CAGGTACAGTTGCCCATCTT & 208 & 59 & 85 \\
\hline
\end{tabular}

${ }^{\mathrm{a} A n n}$. T, annealing temperature; Acq. T, acquisition (fluorescence intensity reading) temperature.

for: Cyp11a1 (P450scc), Hsd3b1 (3ß-HSD1), Cyp21a1 (21-hydroxylase), Cyp11b1 (11ß-hydroxylase), Akr1c18

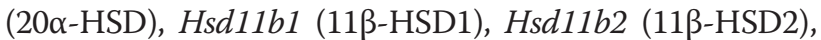
Gapdh (glyceraldehyde-3-phosphate dehydrogenase), and $H m b s$ (hydroxymethylbilane synthase, transcript variant 1 ). For each gene, the relative expression levels were calculated with a standard curve prepared using serial dilutions of an amplicon in $0.1 \mathrm{X}$ reverse transcription buffer. The use of this buffer for dilutions ensured comparable qPCR efficiencies between standard curve samples and lung cDNA samples, as reported [31]. Hmbs and Gapdh expression levels were obtained for all the samples and fed in the GeNorm program to generate a normalization factor for each sample [32]. For all the genes, the mean value obtained on GD 19.5 was fixed as onefold. The suitability of Hmbs and Gapdh as reference genes for normalization of developing lung samples had previously been confirmed [33].

\section{Protein extraction}

Protein extracts were prepared as previously described [33], with slight modifications. Briefly, lung tissues were lysed on ice using a micro-homogenizer (Power max AHS 200, VWR, Ville Mont-Royal, QC, Canada) and 50 to 300 $\mu \mathrm{L}$ of extraction buffer consisting of $50 \mathrm{mM}$ Hepes, pH 7.5, 150 mM NaCl, 1 mM EDTA, 1 mM EGTA, 1 mM NaF, 1\% (v/v) Triton X-100, 10\% (v/v) glycerol, 20 mM $\beta$ glycerophosphate, $8 \mathrm{mM}$ sodium pyrophosphate, and containing a protease inhibitor cocktail (Sigma-Aldrich, St. Louis, MO, USA; $1 \mathrm{mM}$ AEBSF (4-(2-aminoethyl)benzenesulfonylfluoride), $0.8 \mu \mathrm{M}$ aprotinin, $20 \mu \mathrm{M}$ leupeptin, 40 $\mu \mathrm{M}$ bestatin, $15 \mu \mathrm{M}$ pepstatin $\mathrm{A}$, and $14 \mu \mathrm{M}$ E-64, final concentrations). Lysates were centrifuged at $16000 \times \mathrm{g}$ for $20 \mathrm{~min}$ at $4^{\circ} \mathrm{C}$. Total protein concentrations in supernatants were determined using the Bio-Rad protein assay (Bio-Rad, Mississauga, ON, Canada) based on the method of Bradford. Samples were boiled $3 \mathrm{~min}$ in $0.06 \mathrm{M}$ Tris-
$\mathrm{HCl}, \mathrm{pH}$ 6.8, 1\% SDS, 3\% $\beta$-mercaptoethanol, 10\% glycerol, $0.025 \%$ bromophenol blue and then stored at $-20^{\circ} \mathrm{C}$ until use.

For microsomes preparations, samples were homogenized by hand in an all-glass Dounce homogenizer fitted with a B-pestle in ice-cold buffer containing 20\% (vol/ vol) glycerol, $1.0 \mathrm{mM}$ EDTA, and $4 \mathrm{mM}$ potassium phosphate, $\mathrm{pH} 7.0$ (KPBS). Homogenates were centrifuged at $12,000 \times g$ for $20 \mathrm{~min}$ to remove cell debris. The resulting supernatants were centrifuged at $105,000 \times g$ for $60 \mathrm{~min}$. The pellets were resuspended in KPBS and centrifuged again at $105,000 \times g$ for $60 \mathrm{~min}$. The resulting pellets were resuspended in the Triton X-100-containing extraction buffer described above, and saved as micro somes-enriched extracts. Protein concentrations in microsomal fractions were determined as described above.

\section{Western blot analysis and specific antibodies}

Lung protein extracts were separated by sodium dodecyl sulfate-polyacrylamide gel electrophoresis (SDS-PAGE) using 10\% (wt/vol) acrylamide. Then, proteins were transferred to a nitrocellulose membrane (Bio-RAD). Membranes were blocked $2 \mathrm{~h}$ at room temperature with $5 \%$ $(\mathrm{w} / \mathrm{v})$ fat-free milk powder in PBS (1× PBS: $137 \mathrm{mM}$ $\mathrm{NaCl}, 2.68 \mathrm{mM} \mathrm{KCl}, 4.30 \mathrm{mM} \mathrm{Na} \mathrm{HPO}_{4}, 1.47 \mathrm{mM}$ $\left.\mathrm{KH}_{2} \mathrm{PO}_{4}\right)$ containing $0.1 \%(\mathrm{v} / \mathrm{v})$ Tween 20. Membranes were then incubated $1 \mathrm{~h}$ at room temperature with either a mouse anti-rat 21-hydroxylase monoclonal antibody (1:3000; Chemicon International Inc., ON, Canada) or a rabbit anti-Grp78 (Hsp90ß) polyclonal antibody (1:100; Santa Cruz Biotechnology, Santa Cruz, CA, USA) in $1 \mathrm{X} \mathrm{PBS/Tween} 20$ containing $2.5 \%(\mathrm{w} / \mathrm{v})$ fat-free milk. After washing in $1 \mathrm{X} \mathrm{PBS/Tween} \mathrm{20,} \mathrm{bound} \mathrm{antibodies}$ were visualized with horseradish peroxidase-conjugated goat anti-mouse or goat anti-rabbit antibodies (1:5000; Jackson ImmunoResearch Laboratories, West Grove, PA, USA) using a Lumi-Light Western Blotting Substrate 
(Roche Applied Science). Then, antibodies were removed by washing in $62.5 \mathrm{mM}$ Tris- $\mathrm{HCl}, \mathrm{pH} 6.8,2 \%$ (w/v) SDS, $0.7 \%(\mathrm{v} / \mathrm{v}) \beta$-mercaptoethanol for $30 \mathrm{~min}$ at $60^{\circ} \mathrm{C}$. The stripping efficiency was validated with a Lumi-Light Western Blotting Substrate. Membranes were first used to detect 21hydroxylase, stripped, and then re-probed for Hsp90ß.

\section{Statistics}

The effects of age and sex on target gene expression data was assessed by a randomized-block 2-way ANOVA, male and female pools of the same litter being matched. The age of the studied litters was considered as a fixed factor. To ensure that assumptions of normality and homogeneous variances were respected, the dependent variable (expression) was either untransformed (P450scc, 20 $\alpha$ HSD), transformed into its natural log (21-hydroxylase, $11 \beta-$ HSD1 and $11 \beta$-HSD2) or transformed into its reciprocal (3 $\beta$-HSD1). For each gene, comparisons between the mean expression values (calculated with data from both sexes) at specific age-points were performed using the Bonferroni test on selected pairs. The differences were considered statistically significant when $\mathrm{p}<$ 0.05 , whereas for $0.1>p>0.05$, the differences were considered to present a significant trend.

\section{Abbreviations \\ GD: Gestation day; PN: Post-natal day; HSD: Hydroxysteroid dehydrogenase; GC: Glucocorticoid; DOC: Deoxycorticosterone; KO: Knockout; SP: Surfactant} protein; MR: Mineralocorticoid receptor.

\section{Competing interests}

The authors declare that they have no competing interests.

\section{Authors' contributions}

EB carried out the sample collection, performed the GPCR and Western blot experiments, performed the statistical analyses, and participated in the design of the study and in the drafting of the manuscript. PP participated in the design of the study and drafted the manuscript. YT conceived the study, participated in its design, and helped to draft the manuscript. All authors read and approved the final manuscript.

\section{Acknowledgements}

We thank Dr. Manon Richard for critical reading of the manuscript. This work was supported by grants from the Canadian Institutes of Health Research (CIHR) nos. MOP84221, and MOP123232 and from the Natural Sciences and Engineering Research Council of Canada (NSERC) no. 171140-2010.

\section{Author details \\ ${ }^{1}$ Reproduction, mother and youth health, Centre de recherche du $\mathrm{CHU}$ de Québec, Québec, QC, Canada. ²Department of Obstetrics/Gynecology \& Reproduction, Faculty of Medicine, Université Laval, Québec, QC, Canada. ${ }^{3}$ Centre de Recherche en Biologie de la Reproduction (CRBR), Faculté de Médecine, Université Laval, Québec, QC, Canada.}

Received: 17 December 2013 Accepted: 24 February 2014 Published: 1 March 2014

\section{References}

1. Bolt RJ, Van Weissenbruch MM, Lafeber HN, de Wall HA D-v: Glucocorticoids and lung development in the fetus and preterm infant. Pediatr Pulmonol 2001, 32:76-91.

2. Venihaki M, Majzoub J: Animal models of $\mathrm{CRH}$ deficiency. Front Neuroendocrinol 1999, 20:122-145.
3. Wang J, Kuliszewski M, Yee W, Sedlackova L, Xu J, Tseu I, Post M: Cloning and expression of glucocorticoid-induced genes in fetal rat lung fibroblasts. J Biol Chem 1995, 270:2722-2728.

4. Cole TJ, Blendy JA, Monaghan AP, Krieglstein K, Schmid W, Aguzzi A Fantuzzi G, Hummler E, Unsicker K, Schütz G: Targeted disruption of the glucocorticoid receptor gene blocks adrenergic chromaffin cell development and severely retards lung maturation. Genes Dev 1995, 9:1608-1621.

5. Muglia L, Jacobson L, Dikkes P, Majzoub JA: Corticotropin-releasing hormone deficiency reveals major fetal but not adult glucocorticoid need. Nature 1995, 373:427-432.

6. Tomlinson JW, Walker EA, Bujalska IJ, Draper N, Lavery GG, Cooper MS, Hewison M, Stewart PM: 11 beta-hydroxysteroid dehydrogenase type 1: a tissue-specific regulator of glucocorticoid response. Endocr Rev 2004, 25:831-866.

7. Taves MD, Gomez-Sanchez CE, Soma KK: Extra-adrenal glucocorticoids and mineralocorticoids: evidence for local synthesis, regulation, and function. Am J Physiol Endocrinol Metab 2011, 301:E11-E24.

8. Provost PR, Tremblay Y: Genes involved in the adrenal pathway of glucocorticoid synthesis are transiently expressed in the developing lung. Endocrinology 2005, 146:2239-2245.

9. Stocco DM, Clark BJ: Regulation of the acute production of steroids in steroidogenic cells. Endocr Rev 1996, 17:221-244.

10. Simard M, Côté M, Provost PR, Tremblay Y: Expression of genes related to the hypothalamic-pituitary-adrenal axis in murine fetal lungs in late gestation. Reprod Biol Endocrinol 2010, 8:134.

11. Provost PR, Boucher E, Tremblay Y: Glucocorticoid metabolism in the developing lung: adrenal-like synthesis pathway. J Steroid Biochem Mol Biol 2013, 138C:72-80.

12. Giannopoulos G, Keichline D: Species-related differences in steroid-binding specificity of glucocorticoid receptors in lung. Endocrinology 1981, 108:1414-1419.

13. Hellal-Levy C, Couette B, Fagart J, Souque A, Gomez-Sanchez C, Rafestin-Oblin M: Specific hydroxylations determine selective corticosteroid recognition by human glucocorticoid and mineralocorticoid receptors. FEBS Lett 1999, 464:9-13.

14. Rupprecht R, Reul JM, van Steensel B, Spengler D, Soder M, Berning B, Holsboer F, Damm K: Pharmacological and functional characterization of human mineralocorticoid and glucocorticoid receptor ligands. Eur $J$ Pharmacol 1993, 247:145-154.

15. Lu NZ, Wardell SE, Burnstein KL, Defranco D, Fuller PJ, Giguere V, Hochberg RB, McKay L, Renoir JM, Weigel NL, Wilson EM, McDonnell DP, Cidlowski JA: International Union of Pharmacology. LXV. The pharmacology and classification of the nuclear receptor superfamily: glucocorticoid, mineralocorticoid, progesterone, and androgen receptors. Pharmacol Rev 2006, 58:782-797.

16. Shimada H, Miura K, Imamura Y: Characteristics and inhibition by flavonoids of 20alpha-hydroxysteroid dehydrogenase activity in mouse tissues. Life Sci 2006, 78:2931-2936.

17. Milewich L, Smith SL, MacDonald PC: Nonrespiratory functions of the human lung: in vitro metabolism of tritium-labeled progesterone and pregnenolone. J Clin Endocrinol Metab 1980, 50:507-515.

18. Hershkovitz L, Beuschlein F, Klammer S, Krup M, Weinstein Y: Adrenal 20alpha-hydroxysteroid dehydrogenase in the mouse catabolizes progesterone and 11-deoxycorticosterone and is restricted to the X-zone. Endocrinology 2007, 148:976-988.

19. Pelletier G, Luu-The V, Li S, Ren L, Labrie F: Sex-related expression of 20alpha-hydroxysteroid dehydrogenase mRNA in the adult mouse. J Histochem Cytochem 2003, 51:1425-1436.

20. Weisz J, Ward IL: Plasma testosterone and progesterone titers of pregnant rats, their male and female fetuses and neonatal offspring. Endocrinology 1980, 106:306-311.

21. Labrie F: At the cutting edge: intracrinology. Mol Cell Endocrinol 1991, 78:C113-C118.

22. Labrie F, Luu-The V, Lin SX, Simard J, Labrie C, El-Alfy M, Pelletier G, Belanger A: Intracrinology: role of the family of 17 beta-hydroxysteroid dehydrogenases in human physiology and disease. J Mol Endocrinol 2000, 25:1-16.

23. Albiston AL, Obeyesekere VR, Smith RE, Krozowski ZS: Cloning and tissue distribution of the human 11 beta-hydroxysteroid dehydrogenase type 2 enzyme. Mol Cell Endocrinol 1994, 105:R11-R17. 
24. Brown RW, Chapman KE, Kotelevtsev Y, Yau JL, Lindsay RS, Brett L, Leckie C, Murad P, Lyons V, Mullins JJ, Edwards CR, Seckl JR: Cloning and production of antisera to human placental 11 beta-hydroxysteroid dehydrogenase type 2. Biochem J 1996, 313:1007-1017.

25. Martinerie L, Munier M, Le Menuet D, Meduri G, Viengchareun S, Lombes M: The mineralocorticoid signaling pathway throughout development: expression, regulation and pathophysiological implications. Biochimie 2012, 95:148-157.

26. Hirasawa G, Sasano H, Suzuki T, Takeyama J, Muramatu Y, Fukushima K, Hiwatashi N, Toyota T, Nagura H, Krozowski ZS: 11Beta-hydroxysteroid dehydrogenase type 2 and mineralocorticoid receptor in human fetal development. J Clin Endocrinol Metab 1999, 84:1453-1458.

27. Suzuki T, Sasano H, Suzuki S, Hirasawa G, Takeyama J, Muramatsu Y, Date F, Nagura H, Krozowski ZS: 11 beta-hydroxysteroid dehydrogenase type 2 in human lung: possible regulator of mineralocorticoid action. J Clin Endocr Metab 1998, 83:4022-4025.

28. Mustafa SB, DiGeronimo RJ, Petershack JA, Alcorn JL, Seidner SR: Postnatal glucocorticoids induce alpha-ENaC formation and regulate glucocorticoid receptors in the preterm rabbit lung. Am J Physiol Lung Cell Mol Physiol 2004, 286:L73-L80

29. Venkatesh VC, Katzberg HD: Glucocorticoid regulation of epithelial sodium channel genes in human fetal lung. Am J Physiol 1997, 273:L227-L233.

30. Chirgwin JJ, Przbyla AE, MacDonald RJ, Ritter WJ: Isolation of biologically active ribonucleic acid from sources enriched in ribonuclease. Biochemistry 1979, 18:5294-5299.

31. Simard M, Boucher E, Provost PR, Tremblay Y: Minimization of PCR efficiency differences between standards and samples through dilution of PCR amplicons in reverse transcription buffer. Anal Biochem 2007, 362:142-144.

32. Vandesompele J, De Preter K, Pattyn F, Poppe B, Van Roy N, De Paepe A, Speleman F: Accurate normalization of real-time quantitative RT-PCR data by geometric averaging of multiple internal control genes. Genome Biol 2002, 3:RESEARCH0034.

33. Boucher E, Provost PR, Plante J, Tremblay Y: Androgen receptor and 17beta-HSD type 2 regulation in neonatal mouse lung development. Mol Cell Endocrinol 2009, 311:109-119.

doi:10.1186/1756-0500-7-119

Cite this article as: Boucher et al:: Ontogeny of adrenal-like glucocorticoid synthesis pathway and of 20a-hydroxysteroid dehydrogenase in the mouse lung. BMC Research Notes 2014 7:119.

\section{Submit your next manuscript to BioMed Central and take full advantage of:}

- Convenient online submission

- Thorough peer review

- No space constraints or color figure charges

- Immediate publication on acceptance

- Inclusion in PubMed, CAS, Scopus and Google Scholar

- Research which is freely available for redistribution

Submit your manuscript at www.biomedcentral.com/submit
(O) Biomed Central 